\title{
OTOMOBİL SÜRÜCÜ KOLTUĞU KIZAK TASARIMI VE GELIŞTIRILMESI
}

\author{
Ömer Osman DEVECI \\ Ali DURMUS **
}

Alınma: 11.04.2019; düzeltme:26.06.2019; kabul:10.07.2019

Öz: Bu çalışma, Avrupa Birliği ülkelerinde yayınlanan ECE regülasyonu R-14 emniyet kemeri bağlantıları şartları altında çalışan koltuk kızak profil kesiti geliştirilmesi üzerinedir. Kızak profilinde farklı senaryolar oluşturularak regülasyonun şartlarını sağlayıp sağlayamadığı incelenmiştir. Malzeme tipi, sac kalınlığı ve kesit simetri durumu değişkenleri ile farklı senaryolar oluşturulmuştur. Senaryoların modellenmesi CATIA V5'te ve sonlu elemanlar analizleri HyperWorks'te gerçekleştirilmiştir. Seçilen bir senaryonun prototipleri üretilerek test edilmiştir. ECE R-14 regülasyon test sonuçları ile analiz sonuçları karşılaştırılmıştır. Karşılaştırma sonucunda testte elde edilen koltuk sırt yer değiştirme değeri sonlu elemanlarda elde edilen sonuca \% 90 oranında yakın çıkmıştır.

Anahtar Kelimeler: Otomobil Sürücü Koltuğu, Koltuk Kızağı, Kızak Profil Kesit Tasarımı, ECE R-14

\section{The Automobile Driver Seat Track Design and Development}

Abstract: This study concerns about seat tracks which are designed and developed for passing Economic Commission for Europe (ECE) R-14 regulation. Main focus on the seat track design is profile sections. Alternative scenarios are created and validated according to the regulation criteria's. In the scenarios; the material type, thickness and section symmetry parameters have been combined. The CAD models are designed in CATIA V5 and transferred to HyperWorks for FEA's. In order to verify the results of FEA's, prototypes are produced and tested. The paper also discusses the FEA results which are compared and validated with the test results. As a result of the comparison, the seat back displacement correlation ratio was obtained $90 \%$ in the tests.

Keywords: Automobile Driver Seat, Seat Track, Track Profile Section Design, ECE R-14

\section{GİRIŞ}

Fosil yakıtı tüketen araçlarda doğaya salınan karbondioksit miktarına ait yasal düzenlemelerin daha da sıkılaşması ve buna bağlı olarak ağırlık azaltma ve motor verimlerinin artması dolayısı ile daha uzun süreli seyahatler mümkün olabilmektedir. Uzun süren seyahatler, özellikle sürücünün oturduğu koltuğun daha konforlu ve kaza esnasında emniyetli olmasını gerektirmiştir. Konfor şartlarını oturak ve sırt bölgesindeki sünger ve koltuk kılıfları sağlarken, hem emniyet hem de konfor özelliklerini belirleyen koltuk mekanizmalarıdır. Sürüş konumunu ve sürücünün oturma pozisyonunu belirlediği için mekanizmalar oldukça önemlidir. Başlıca koltuk mekanizmaları; araç yönüne göre öne-arkaya hareketi sağlayan kızak mekanizması, oturak ve sırtı birbirine bağlayan ve sırt açısını ayarlayan sırt yatırma mekanizması ve oturak

\footnotetext{
* Martur A.Ş., Bursa Organize Sanayi Bölgesi, Kahverengi Caddesi, No: 9, 16140, Nilüfer, Bursa

** Bursa Uludağ Üniversitesi, Mühendislik Fakültesi, Makine Mühendisliği Bölümü, Bursa

İletişim Yazarı: Ali DURMUŞ (adurmus@uludag.edu.tr)
} 
yüksekliğini ayarlayan yükseklik ayar mekanizmasıdır. Literatürde bu mekanizmaların geliştirilme yöntemleri üzerine çalışmalar bulunmaktadır.

Sang ve diğ (2010) koltuk yapılarının güncel gelişmelerine genel bir bakış sunmakta ve koltuk iskelet tasarımı, optimizasyonu ve doğrulaması için bir geliştirme prosedürü sunmaktadır. Çalışmada, sonuç olarak rekabetçi bir koltuk iskelet tasarımı gösterilmiş ve bundan bir tasarım rehberi ve standart bir ürün geliştirme prosedürü oluşturulmuştur. Mazur ve diğ. (2011) çalışmalarında kızak profil kesitlerinin üretim şartlarındaki boyutsal şekil değişimin kızak kayma performansına etkisini incelemiştir. Farklı kesite haiz ürünlerin üretim değişkenlikleri nedeni ile boyutsal özelliklerinin farklılı̆̆ını kıyaslayarak, kızak profillerinin en uygun olanının hızlı değerlendirilmesini ve sistematik olarak seçimini ortaya koymuştur. Peicheng ve Zengwei (2018) ön koltukların, emniyet kemerlerinin ve dummy'lerin ön işlemlerini HyperWorks sonlu elemanlar analiz yazılımında, çözümünü ise LS-DYNA'da gerçekleştirmişlerdir. Çalışmalarında yasal gereklilikleri karşılayan, fiziksel testlerin sayısını azaltan ve tasarım döngüsü süresini kısaltan bir yöntem ortaya konmuştur. Arslan ve Kaptanoğlu (2010) çalışmalarında ECE R-14 regülasyonuna tabi tutulan ön ve arka koltukların bağlantılarının sonlu elemanlar ile analizlerini gerçekleştirmiş ve testlerle doğrulamıştır. Deveci ve diğg. (2018) ECE R-14 şartlarında kızak profillerine gelen yüklerin global eksene göre yaptığ teorik açıların tespiti üzerine çalışmıştır. Regülasyona uygunluğu öncelikle tekil kızak üstünde analiz ederek yeni ürün geliştirme sürecinde çevrim zamanını azaltmıştır. Pişgin ve Solmaz (2018) çalışmalarında mevcutta ECE R-14 testlerini geçen üç noktadan destekli emniyet kemerli bir koltuğun, iki sabit noktasını üzerinde taşıyan ve kaza anında üzerine düşen kuvvetlere dayanımı artırılmış sürücü koltuğu geliştirmiştir.

$\mathrm{Bu}$ çalışmada ise koltuk kızaklarının kesitinde tasarım değişkenleri bir araya getirilerek farklı senaryolar oluşturulmuştur. ECE R-14 emniyet kemeri bağlantıları regülasyonuna göre performansları incelenmiş ve performansa etki eden tasarım değişkenlerinin etki yüzdeleri hesaplanmıştır. Çalışmanın amacı; üç nokta emniyet kemerli sürücü koltuğu kızaklarının dayanımından ödün vermeden ağırlığının azaltılmasını sağlayacak geliştirmelere yol göstermek ve nihai ürün güvenliğini artırmaktır.

\section{MATERYAL VE YÖNTEM}

\section{1. Ön Koltuk Kızak Mekanizması}

Tasarım programı olarak CATIA V5 (Dassault Systèmes, 2004) kullanılmıştır. Çalışmada detaylandırılacak mekanizmanın koltuk üzerindeki konumu ve kızak mekanizması Şekil 1a ve 1b'de gösterilmektedir. Kızak mekanizması dışındaki diğer koltuk elemanları her bir senaryo için ortak kullanılmıştır.

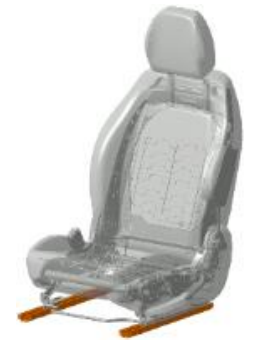

$a$.

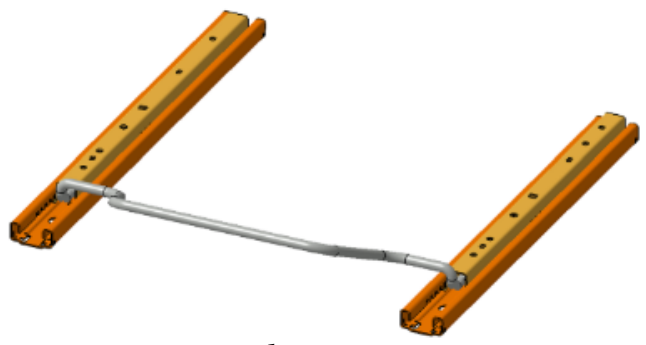

$b$.

Sekil 1:

Çalışma konusu parçaların gösterimi;

a. Koltuk komplesi b. Kizak mekanizması 
Kızak mekanizması, koltuğun araç doğrultusuna göre öne-arkaya konum ayarı yapılmasını ve bu konumda sabit kalmasını sağlayan sistemdir. Her koltukta iç ve dış olmak üzere 2 adet tekil kızak mekanizması bulunur (Şekil 2a). Birbiri içine geçen üst-alt kızak profilleri ve her iki profil arasında bulunan yuvarlanma elemanları Şekil 2b'de kesit olarak gösterilmiştir. Kızağın koltuk ile bağlantısı üst profil üzerinden, araç zeminine bağlantısı alt profil üzerinden gerçekleşir. Yuvarlanma elemanlarının görevi, kızakların birbirine göre konumları değişirken düşük yükler altında koltuğun hareket etmesini sağlamaktır. Diğer bir görevi, üst profile etki eden kuvvetlerin alt profile geçişini sağlayacak köprüdür.

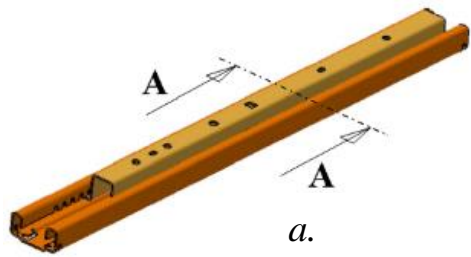

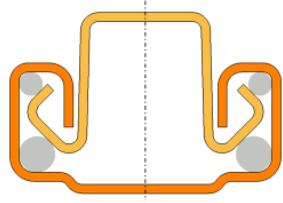

$b$.

\section{Şekil 2:}

Katı modelleri oluşturulmuş parçaların gösterimi;

a. Tekil kızak mekanizması b. Klzak kesit A-A gösterimi

\subsection{Tasarıma Etki Eden Değişkenler}

$\mathrm{Bu}$ çalışmada, kızak mekanizması kesit performansına etki eden malzeme, kesit kalınlığ ve eksene göre simetri durumu gibi birbirinden farklı değişkenler üzerinde durulmuştur. $\mathrm{Bu}$ değişkenlere ait detaylar aşağıda açıklanmaktadır.

Malzeme; profil malzemesi ürün performansını doğrudan etkilemektedir. Yüksek mukavemetli çeliklerden seçilen 2 tip profil malzemesine ait mekanik özellikler Tablo 1'de verilmiştir. Yuvarlanma elemanlarına malzeme tanımı yapılmadan rijit eleman olarak bırakılmıştır.

Tablo 1. Profil malzemeleri fiziksel özellikleri (Tata Steel, 2014a ve 2014b)

\begin{tabular}{|l|c|c|c|}
\hline Malzeme Ad1 & $\begin{array}{c}\text { Min. Akma } \\
\text { Dayanımı (MPa) }\end{array}$ & $\begin{array}{c}\text { Min. Çekme } \\
\text { Dayanımı (MPa) }\end{array}$ & Maks. Uzama (\%) \\
\hline S500MC & 560 & 650 & 20 \\
\hline S700MC & 750 & 810 & 10 \\
\hline
\end{tabular}

Kesit kalınlığı; kızak profillerine ait malzeme kesit kalınlığı T1:2,0 mm, T2:1,8 mm ve T3:1,6 mm olacak şekilde değişken olarak tanımlanmıştır (Şekil 3). Profil skeçleri tasarım programında tam parametrik olarak ölçülendirildiği için, kalınlık değişimi belirtilen sınır şartlarını koruyacak şekilde sorunsuz yapılabilmektedir.

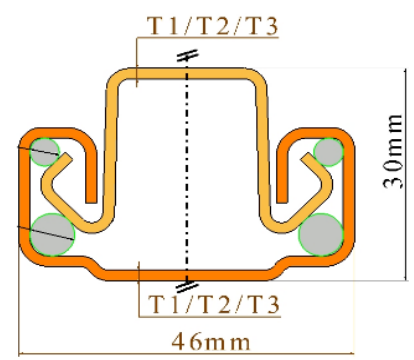

Şekil 3: 


\section{Kesit üstünde kalınlık gösterimi}

Eksene göre simetri durumu; profil kesitinin orta eksene göre simetri olarak tasarlandığ1 durum "SYM: Simetrik" (Şekil 4a) ve simetri olmadığı durum "ASYM: Asimetrik" olarak adlandırılmıştır (Şekil 4b).

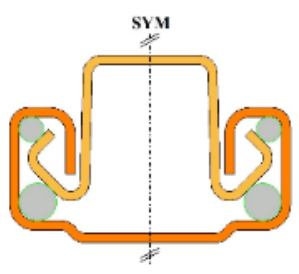

$a$.

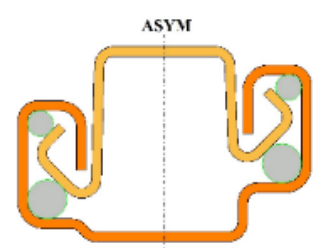

$b$.

Şekil 4:

Kesit simetri gösterimleri;

a. SYM: Simetrik tasarım kesiti b. ASYM: Asimetrik tasarm kesiti

Bu değişkenlere göre 12 ayrı senaryo Tablo 2'de gösterilmektedir. Son sütunda kesitin kızak ağırlığına etkisinin hesabı için gerekli olan kesit alanı, tasarım programında katı modeller üzerinden ölçülerek verilmiştir.

Tablo 2. Tasarım senaryoları

\begin{tabular}{|l|c|c|c|c|}
\hline Senaryo No & Malzeme Ad1 & $\begin{array}{c}\text { Kesit Kalınlı̆̆ } \\
(\mathrm{mm})\end{array}$ & Simetri Durumu & $\begin{array}{c}\text { Kesit Alanı } \\
\left(\mathrm{mm}^{2}\right)\end{array}$ \\
\hline Senaryo \#01 & S500MC & 2,0 & Simetrik & 410,4 \\
\hline Senaryo \#02 & S500MC & 1,8 & Simetrik & 375,2 \\
\hline Senaryo \#03 & S500MC & 1,6 & Simetrik & 338,8 \\
\hline Senaryo \#04 & S700MC & 2,0 & Simetrik & 410,4 \\
\hline Senaryo \#05 & S700MC & 1,8 & Simetrik & 375,2 \\
\hline Senaryo \#06 & S700MC & 1,6 & Simetrik & 338,8 \\
\hline Senaryo \#07 & S500MC & 2,0 & Asimetrik & 410,4 \\
\hline Senaryo \#08 & S500MC & 1,8 & Asimetrik & 375,2 \\
\hline Senaryo \#09 & S500MC & 1,6 & Asimetrik & 338,8 \\
\hline Senaryo \#10 & S700MC & 2,0 & Asimetrik & 410,4 \\
\hline Senaryo \#11 & S700MC & 1,8 & Asimetrik & 375,2 \\
\hline Senaryo \#12 & S700MC & 1,6 & Asimetrik & 338,8 \\
\hline
\end{tabular}

\subsection{Sonlu Elemanlar Analiz Çalışmaları}

Koltuk mekanizmalarının ayar pozisyonları koltuğun performansını etkilemektedir. Bu sebeple regülasyonda mekanizma pozisyonları özellikle belirtilmiştir. Bu pozisyonlar; kızak mekanizması: en arka, yükseklik ayar mekanizması: en alt ve sırt yatırma mekanizması: sırt açısı $25^{\circ}$ konumudur.Senaryolara ait katı modeller sonlu elemanlar yazılımı HyperWorks'e (Altair Engineering Inc., 2017a) aktarılmıştır. HyperWorks üstünde profil kesit kalınlığının parametrik olarak tanımlanması için profillerin orta eksen yüzeyleri çıkarılarak mesh atılmıştır. Kesitin daha iyi gösterimi için 2 boyutlu elemanların temsili görüntüsü Şekil 5a'daki gibidir. Analiz süresini uzatmamak için tüm mesh elemanın boyları en az $8 \mathrm{~mm}$ 
tutulmuştur (Şekil 5b). Mesh atılırken üçgen elemanların toplam eleman sayısının \% 20'ini geçmemesine dikkat edilerek mesh kalitesi artırılmıştır. Üst profile 7596 adet düğüm noktasını oluşturacak (node) toplam 7272 adet üçgen (trias) ve dörtgen (quad) eleman atılmıştır. Alt profile de 11114 düğüm noktasını oluşturacak 10821 adet eleman atılmıştır.

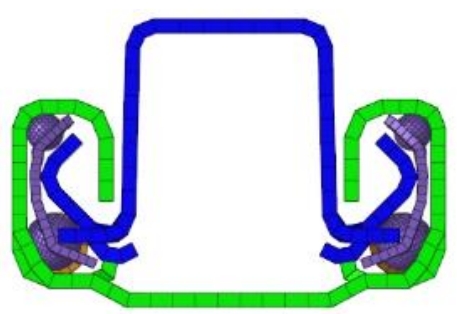

a.
Şekil 5:

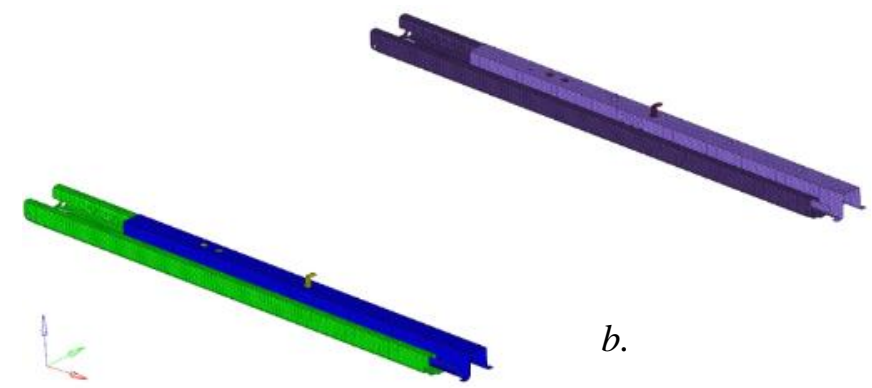

Mesh model gösterimleri;

a. Mesh kesiti b. Komple kizak mesh modeli

Yapı oluşturulurken 2 tip kontak kullanılmıştır; yüzey-yüzey kontak, kenar-kenar kontak.

Etki eden kuvvetlerin hesabında, üç nokta emniyet kemerine sahip M1 sınıfı (United Nations, 2017) araçlar üzerine etkiyen kuvvetler ve uygulaması Şekil 6'da gösterilmiştir. Omuz kemerine - üst blok (F1) ve bel emniyet kemerlerine - alt blok (F2) siras1 ile 1 ve 2 numaralı denklemlerdeki kuvvetler yatay Y ekseni ile $10^{\circ} \pm 5^{\circ}$ açı ile etki etmektedir. Hesaplamalarda kullanılan koltuk kütlesi yaklaşık 23 kg'dır.

$$
\mathrm{F} 1=13500 \mathrm{~N}
$$

$$
\mathrm{F} 2=13500 \mathrm{~N}+20 \times \text { koltuk kütlesi } \times 9,81 \frac{\mathrm{m}}{\mathrm{s}^{2}}=18000 \mathrm{~N}
$$

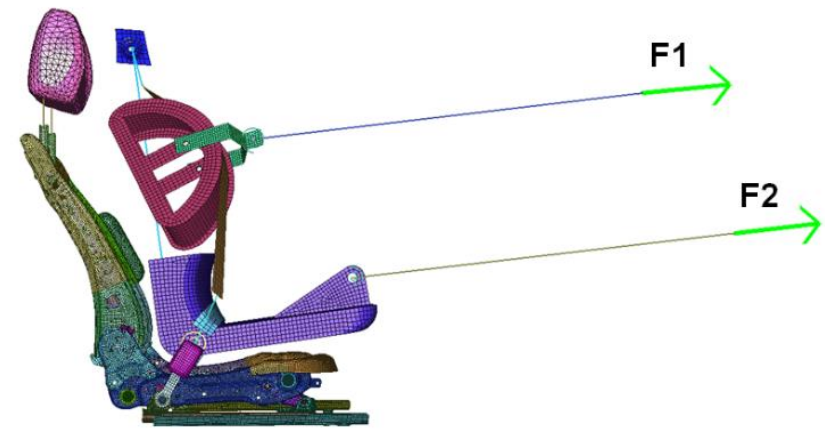

\section{Şekil 6:}

Sonlu elemanlar analizinde etki eden kuvvetler ve uygulanışları

Regülasyonda sınır şartları olarak; çekme kuvvetlerine en hızlı şekilde ulaşılması ve yapının belirtilen kuvvetlere 0,2 saniye dayanması tanımlıdır. Buradan yola çıkarak sonlu elemanlar programında kuvvet-zaman girişleri elle yapılarak Şekil 7a ve 7b'deki grafikler elde edilmiştir. 


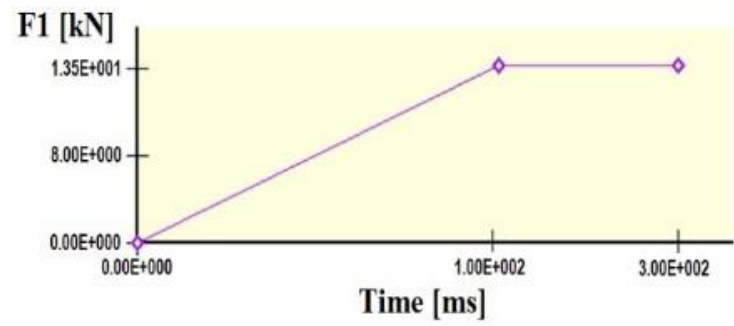

$a$.

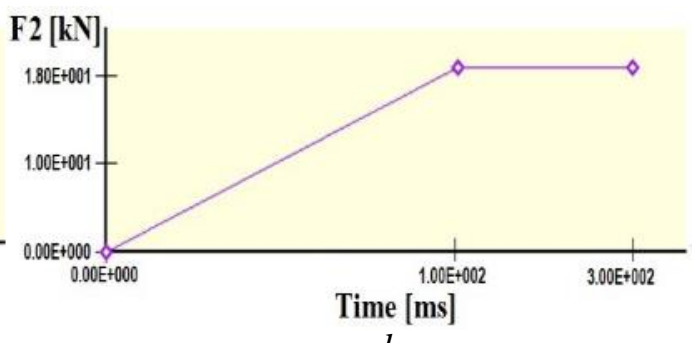

$b$.

Şekil 7:

Kuvvet-Zaman grafiklerinin gösterimi;

a. F1'e ait grafik b. F2'ye ait grafik

Sonlu elemanlar analiz programında gerinim değerleri 0-300 milisaniye anında program üstünden alınabilmektedir. Bu yöntemle 0 milisaniye anı (Şekil 8a) ile 300 milisaniye anında (Şekil 8b) büyütülmüş renk çizelgesine karşılık gelen değerler (Şekil 8c) okunabilmektedir.

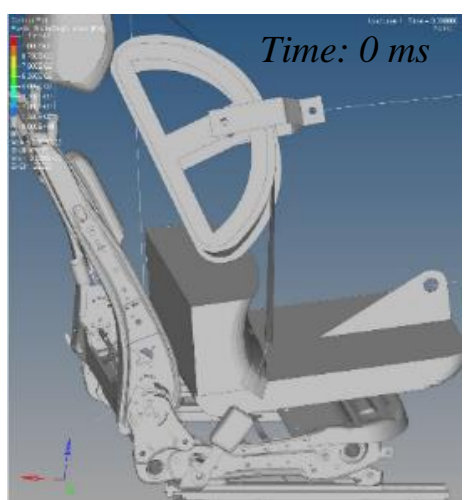

a.

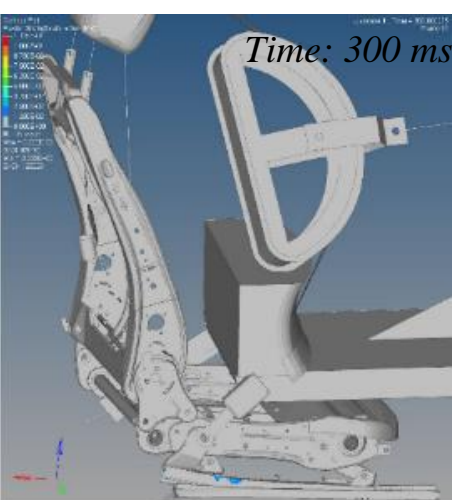

$b$.

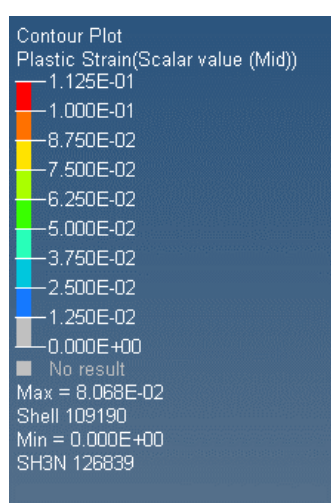

$c$.

Şekil 8:

Sonlu elemanlar analizinin başlangıç ve bitiş anı gösterimi;

a. 0. milisaniye b. 300. milisaniye c. Büyütülmüss renk çizelgesi

Analizler için gerekli tüm girişlerin tamamlanmasının ardından kapalı çözüm (explicit) metodu kullanılarak modeller Radioss (Altair Engineering Inc., 2017b) ile çözdürülmüştür. Çözümde 8 fiziksel çekirdekli 3,0 GHz işlemci kullanılmış ve analiz başına ortalama çözüm 97200 saniye sürmüştür.

\subsection{Prototip Çalışmaları}

Sonlu elemanlar çalışmalarının güvenilirliğini artırmak için fiziksel testlerle desteklenmesi gerekmektedir. Test etmek amacıyla, belirlenen senaryolar arasından sürücü koltuklarında kullanımı en yaygın olan (http://www.a2mac1.com) senaryo \#05, prototip üretimi için seçilmiştir. Bu senaryonun öncelikle prototip kalıpları tasarlanmış ve üretilmiştir. Ardından profil üretimine geçilmiş ve test ihtiyaçlarını karşılayacak adette fiziksel parçalar üretilmiştir (Şekil 9a ve 9b). Üretilen parçaların montajı elle yapılarak kızak kompleleri oluşturulmuştur. Mekanizmanın çalışma kontrolleri koltuk oturağına monte edilerek yapılmıştır (Şekil 9c). 


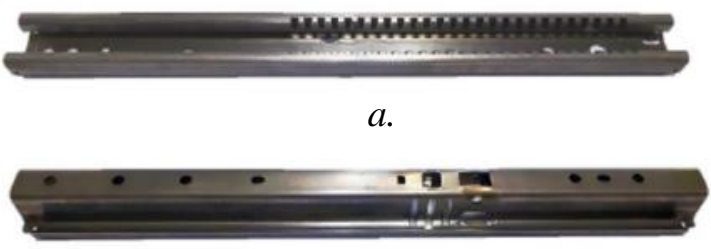

$b$.

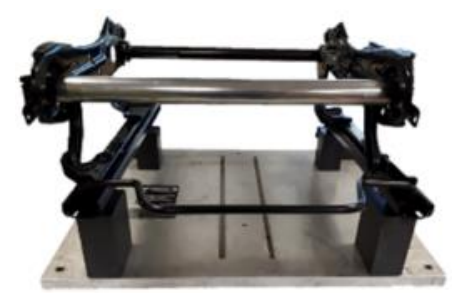

c.

\section{Sekil 9:}

Prototip kızaklar (Martur A.Ş.);

a. Alt profil prototipi $\boldsymbol{b}$. Üst profil prototipi $\boldsymbol{c}$. Koltuk oturağına monte edilmis komple klzak

\section{BULGULAR VE TARTIŞMA}

Sonlu elemanlar analizi sonucunda tüm sistemdeki plastik gerinim (strain) değerleri, "vonMises" gerilme değerleri ve koltuk sırt kısmının yer değiştirmeleri incelenmiştir. Başarı kıstası, bileşenlerde görülen en yüksek plastik gerinim değerinin malzemenin kopmadaki plastik gerinim değerinden düşük olması ve sırt yer değiştirmenin 250 mm'den küçük olmasıdır. Senaryolara göre kızak profillerine ait sonlu elemanlar sonuçları Tablo 3'te verilmiştir. Sonuçlarda maksimum yüke dayanmadan alt-üst profili birbirinden ayrılan senaryolar "uygun değil" olarak belirtilmiştir.

Tablo 3. Kızak profilleri sonlu elemanlar sonuçları

\begin{tabular}{|l|c|c|c|c|}
\hline Senaryo No & $\begin{array}{c}\text { Plastik Gerinim } \\
(\%)\end{array}$ & $\begin{array}{c}\text { von-Mises Mukayese } \\
\text { Gerilmesi (MPa) }\end{array}$ & $\begin{array}{c}\text { Yer Değiştirme } \\
(\mathrm{mm})\end{array}$ & Sonuç \\
\hline Senaryo \#01 & 7,1 & 581 & 54 & Uygun \\
\hline Senaryo \#02 & 7,8 & 638 & 65 & Uygun \\
\hline Senaryo \#03 & 27 & 695 & 260 & Uygun değil \\
\hline Senaryo \#04 & 0,1 & 602 & 47 & Uygun \\
\hline Senaryo \#05 & 0,2 & 680 & 53 & Uygun \\
\hline Senaryo \#06 & 7 & 784 & 68 & Uygun \\
\hline Senaryo \#07 & 6,5 & 566 & 51 & Uygun \\
\hline Senaryo \#08 & 7,2 & 627 & 59 & Uygun \\
\hline Senaryo \#09 & 26 & 702 & 260 & Uygun değil \\
\hline Senaryo \#10 & 0,08 & 599 & 45 & Uygun \\
\hline Senaryo \#11 & 0,2 & 677 & 51 & Uygun \\
\hline Senaryo \#12 & 6,5 & 778 & 65 & Uygun \\
\hline
\end{tabular}

Regülasyona uygunluk testleri, Martur A.Ş. bünyesindeki emniyet kemer çekme test cihazında gerçekleştirilmiştir. Şekil 10'da gösterilen bu test cihazındaki 2 adet hidrolik piston çekme kuvvetlerini oluşturmaktadır. 


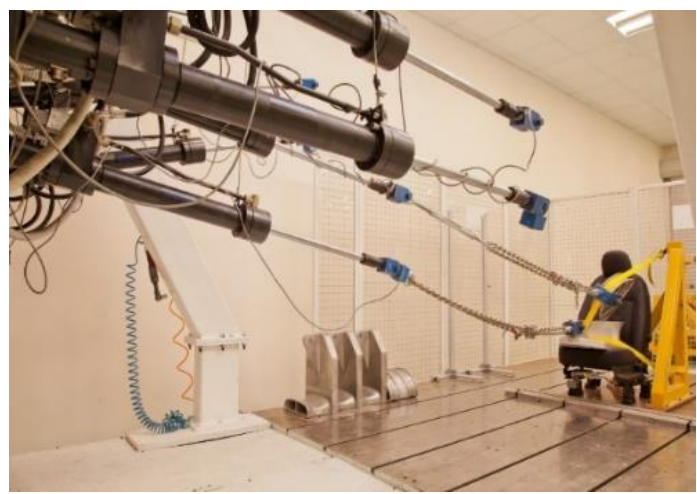

Şekil 10:

Emniyet kemer çekme test cihazı (Martur A.Ş.)

F1 ve F2 kuvvetleri 2 aşamada uygulanmaktadır. Birinci aşama; mümkün olan en kısa sürede istenen kuvvetlere çıkılması, ikinci aşama; bu kuvvetler altında bekletilmesidir (Şekil 11). Regülasyonda bekleme süresi için istenen en az 0,2 saniye olmasına rağmen en az 3 saniye bekletilerek testin güvenirliliği artırılmıştır.

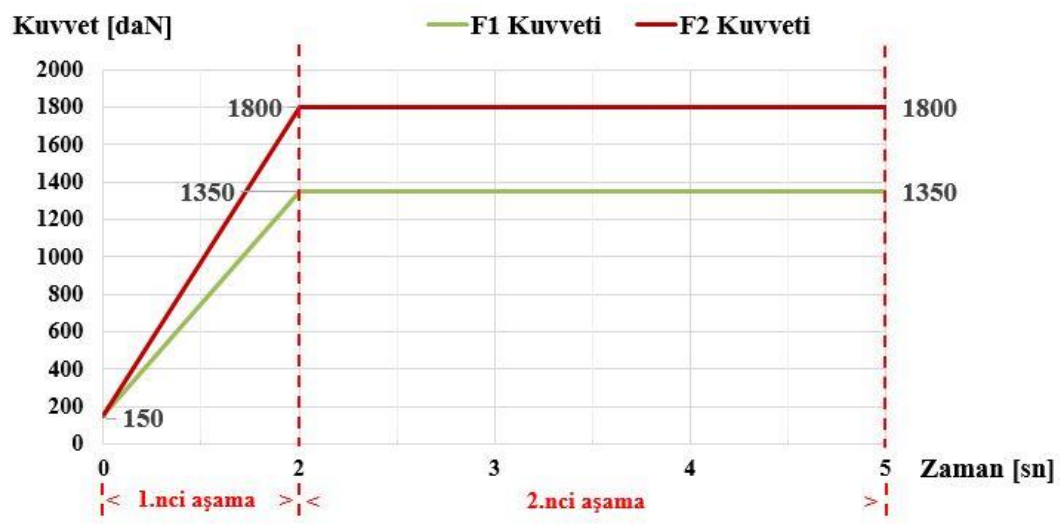

Şekil 11:

2 aşamalı F1 ve F2 Kuvvet-Zaman grafiği gösterimi

ECE R-14 regülasyonu açısından uygunluk kriteri; emniyet kemerinin bağlandığı komple yapının bütünlügünü koruması ve yapıya bağlı kalmasıdır. Deplasman kıstası olarak; koltuk sırt bölgesinin, koltuk $\mathrm{H}$ noktasından geçen düşey düzlemle $10^{\circ}$ açı yapan sınır düzleminin çekme yönüne göre geride kalmasıdır. Buradan yola çıkılarak hesaplanan yer değiştirme sınır değeri yaklaşık $250 \mathrm{~mm}$ 'dir.

Fiziksel testler 6 adet prototip üzerinde yapılmıştır. Tablo 4'te testlerin regülasyona göre sonuçları gösterilmektedir. Koltuk sırt bölgesinden ölçülen yer değiştirmelerin analiz bulguları ile kıyaslaması ve korelasyon yüzdeleri yine aynı tabloda gösterilmiştir. Korelasyon yüzdelerinin aritmetik ortalaması \% 90 bulunmuştur. 
Tablo 4. Emniyet kemer çekme test sonuçları

\begin{tabular}{|c|c|c|c|c|}
\hline Test No & $\begin{array}{c}\text { Testte Sirt Yer } \\
\text { Değiştirme } \\
\text { Miktar1 }(\mathrm{mm})\end{array}$ & $\begin{array}{c}\text { Sonlu Elemanlarda Sirt } \\
\text { Yer Değiştirme Miktarı } \\
(\mathrm{mm}) \text { Sonucu }\end{array}$ & Korelasyon (\%) & Sonuç \\
\hline Test \#01 & 72 & 65 & 90,3 & Uygun \\
\hline Test \#02 & 74 & 65 & 87,8 & Uygun \\
\hline Test \#03 & 70 & 65 & 92,9 & Uygun \\
\hline Test \#04 & 69 & 65 & 94,2 & Uygun \\
\hline Test \#05 & 75 & 65 & 86,7 & Uygun \\
\hline Test \#06 & 72 & 65 & 90,3 & Uygun \\
\hline
\end{tabular}

Testten sonra kızakta oluşan deformasyonun en yüksek olduğu bölgelere ait detay görüntüler Şekil 12a ve 12b'de verilmiştir.

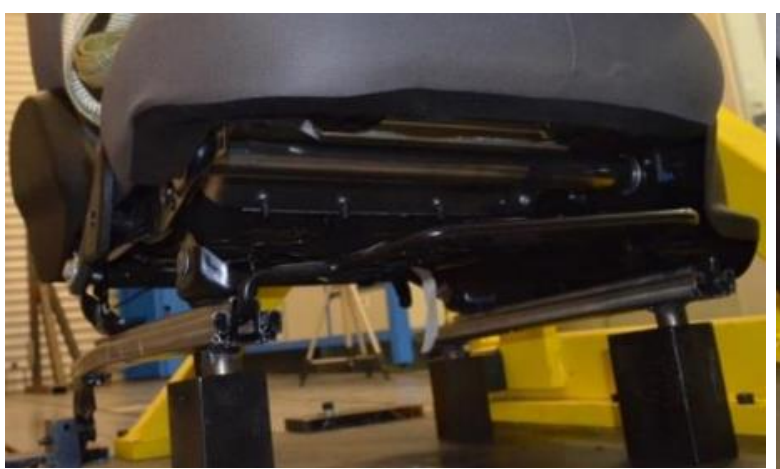

a.

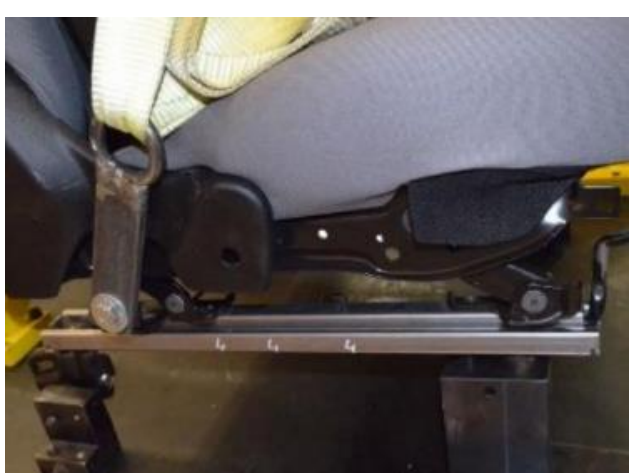

$b$.

Şekil 12:

Emniyet kemer çekme test sonrası görünüş (Martur A.Ş.);

$\boldsymbol{a}$. Kızak perspektif görünüş b. Kızak yandan görünüş

\section{SONUÇ}

Bu çalışmada koltuk kızaklarının tasarımında farklı senaryolar oluşturulmuş, ECE R-14 emniyet kemeri bağlantıları regülasyonuna göre performansları incelenmiştir. Çalışmada yürütülen tüm analiz ve testlerin sonuçları regülasyon gerekliliklerine göre değerlendirilmiştir. Çalışma kapsamında incelenen değişkenlerden kesit kalınlığının tek başına azaltılması gerinim değerlerini artırmıştır. Ancak malzemesi S700MC olan senaryolarda malzemeye bağlı mukavemet artışı, azalan kesit kalınlığına bağlı mukavemet düşüşünü karşılamıştır. Diğer bir değişken olarak kesitin simetrik veya asimetrik olması, sonuçlarda sadece $\% 8$ pozitif etkisi olmuştur. Bu değer dikkate alındığında tasarım ihtiyaçlarına göre her iki tip kesit birbiri yerine kullanılabilir. Plastik gerinim yüzdelerine göre sonuçlar sıralandığında, tasarım parametrelerinden sonuca en fazla etkiyi malzeme değişkeninin sebep olduğu görülmüştür. Seçilen senaryonun sonlu elemanlar ve test sonuçları arasında sırt yer değiştirmesi dikkate alınarak hesaplanan korelasyon \% 90'dir. Diğer senaryolar her ne kadar üretilip test edilmemiş olsa da bu korelasyon yüzdesi ile diğer senaryoların fiziksel testlerinde de sonlu elemanlarda elde edilen sonuçlara yakın değerler elde edileceği ön görülmektedir. 


\section{TEŞEKKÜR}

Prototip üretimi ve test imkânlarını sunan Martur A.Ş.'ye teşekkür ederiz. Bu çalışma, Ömer Osman DEVECI'nin devam eden yüksek lisans çalışmalarından hazırlanmıştır.

\section{KAYNAKLAR}

1. Altair Engineering Inc. (2017a), Altair HyperWorks HyperMesh User Guide.

2. Altair Engineering Inc. (2017b), Altair HyperWorks RADIOSS Tutorials and Examples.

3. Arslan, A. ve Kaptanoğlu, M. (2010), Bir ticari araç için ECE R-14 regülasyonuna uygun koltuk bağlantılarının geliştirilmesi, OTEKON 2010 5. Otomotiv Teknolojileri Kongresi.

4. Dassault Systèmes (2004), CATIA V5 User Guides, Part Design, Assebmly Design, Wireframe and Surface, Version 5 Release 14.

5. Deveci, Ö., Sarısaç, S., Düvenci, F., Durmuş, A. (2018), Binek araç ön koltuklarında kullanılan kızak mekanizmasının dayanım doğrulama metodolojisi, OTEKON 20189. Otomotiv Teknolojileri Kongresi, s1656-s1661.

6. Pişgin E. ve Solmaz E. (2018), FMVSS 210 Normuna göre sürücü koltuğu geliştirilmesi, Uludağ Üniversitesi Mühendislik Fakültesi Dergisi, Cilt 23, Say1 1. Doi: 10.17482/uumfd.390068

7. Gavelin, A., Iraeus, J., Lindquist, M., Oldenburg, M. (2010) Evaluation of finite element models of seat structures with integrated safety belts using full scale experiments, International Journal of Crashworthiness Tandfonline, Taylor \& Francis 15:3, 265-280. Doi: 10.1080/13588260903250994

8. http://www.A2mac1.com, Erişim Tarihi: 15.03.2019, Konu: Seats > Driver > Adjuster > Longitudinal > Rails alt başlık içinde klyaslanan kızaklar.

9. Mazur, M., Leary, M., Huang, S., Baxter, t., Subic, A. (2011), Benchmarking study of automotive seat track sensitivity to manufacturing variation, International conference on engineering design, ICED11.

10. Peicheng, S. ve Zengwei, X. (2018), Analysis of seat belt anchorage strength for vehicles, IOP Conf. Series: Materials Science and Engineering, 301 (2018) 012127. Doi: 10.1088/1757-899X/301/1/012127

11. Sang, D.P., Jong, K.P., Byung, Y.C., Dong, W.J., Hak, G.K. (2010) Seat Common Frame Design Optimization, SAE Technical Paper, 2010-01-0390. Doi:10.4271/2010-01-0390.

12. TATA Steel (2014a), Ympress S500MC data sheet

13. TATA Steel (2014b), Ympress S700MC data sheet

14. UNECE (2012), ECE R-14 Uniform provisions concerning the approval of vehicles with regard to safety-belt anchorages, ISOFIX anchorages systems and ISOFIX top tether anchorages

15. United Nations (2017), Consolidated Resolution on the Construction of Vehicles (R.E.3). ECE/TRANS/WP.29/78/Rev.6 